Chung-Chih Kuo, Ruei-Jen Chiou, Keng-Chen Liang and Chen-Tung Yen

J Neurophysiol 101:1201-1210, 2009. First published Dec 17, 2008; doi:10.1152/jn.90347.2008

You might find this additional information useful...

This article cites 71 articles, 16 of which you can access free at:

http://jn.physiology.org/cgi/content/full/101/3/1201\#BIBL

Updated information and services including high-resolution figures, can be found at:

http://jn.physiology.org/cgi/content/full/101/3/1201

Additional material and information about Journal of Neurophysiology can be found at: http://www.the-aps.org/publications/jn

This information is current as of May 7, 2009 .

Journal of Neurophysiology publishes original articles on the function of the nervous system. It is published 12 times a year (monthly) by the American Physiological Society, 9650 Rockville Pike, Bethesda MD 20814-3991. Copyright (C) 2005 by the American Physiological Society. ISSN: 0022-3077, ESSN: 1522-1598. Visit our website at http://www.the-aps.org/. 


\title{
Differential Involvement of the Anterior Cingulate and Primary Sensorimotor Cortices in Sensory and Affective Functions of Pain
}

\author{
Chung-Chih Kuo, ${ }^{1,2}$ Ruei-Jen Chiou, ${ }^{3,4}$ Keng-Chen Liang, ${ }^{5}$ and Chen-Tung Yen ${ }^{4}$ \\ ${ }^{1}$ Institute of Neuroscience and ${ }^{2}$ Institute of Physiological and Anatomical Medicine, Tzu Chi University, Hualien; ${ }^{3}$ Department \\ of Anatomy, Taipei Medical University; and ${ }^{4}$ Institute of Zoology and ${ }^{5}$ Department of Psychology, National Taiwan University, \\ Taipei, Taiwan
}

Submitted 10 March 2008; accepted in final form 15 December 2008

\begin{abstract}
Kuo C-C, Chiou R-J, Liang K-C, Yen C-T. Differential involvement of the anterior cingulate and primary sensorimotor cortices in sensory and affective functions of pain. J Neurophysiol 101: 1201-1210, 2009. First published December 17, 2008; doi:10.1152/jn.90347.2008. The present study examined the role of neurons in different pain-related functions of the anterior cingulate cortex (ACC) and primary sensorimotor cortex (SmI) by assessing their abilities to code different levels of noxious heat and activity changes evoked by classical fear conditioning involving electric shocks. Multiple single-unit activity was recorded with microwires implanted in the SmI and ACC of each rat. In the first set of experiments, the middle segment of the tail in each rat was irradiated with laser-heat pulses of various intensities. Neuronal responses in both the SmI and ACC increased with the intensity of the laser heat, although there was a significantly higher percentage of intensity-related units in the SmI. Furthermore, the stimulus-response curve of SmI ensemble activity had a steeper slope than that of the ACC. In the second set of experiments, rats were trained and tested on a conditioned fear-potentiated startle task in which a light was paired with an electric shock and, later, the startle response was elicited by a burst of noise in the presence or absence of light. A higher percentage of ACC units changed their neuronal responses to the conditioned stimulus after the light-shock pairing and the average activity change was also significantly stronger. Our results suggest that SmI neurons are better at coding laser-heat intensity than ACC neurons, whereas more ACC neurons are involved in conditioned fear associated with an electric shock than SmI neurons. These data provide evidence for differential contributions of the SmI and ACC to sensory and affective dimensions of pain.
\end{abstract}

\section{N T R O D U C T I O N}

Pain, a complex experience that alerts an organism about imminent danger, induces negative emotions including unpleasantness, anxiety, and fear and thus motivates the subject to avoid further damage. A prevailing hypothesis suggests that pain has three components: sensory discrimination, affective motivation, and cognitive evaluation (Melzack and Casey 1968; Price and Dubner 1977). Accordingly, a substantial amount of effort has been expended to locate the neural substrate subserving each of these components. Neural imaging studies on human subjects have been informative in identifying brain areas involved in processing the various aspects of pain. The most consistently engaged areas found in such studies include the primary somatosensory $(\mathrm{SmI})$ and anterior cingulate cortices (ACC) (Apkarian et al. 2005; Bingel et al. 2003, 2004; Buffington et al. 2005; Chen et al. 2002; Koyama

Address for reprint requests and other correspondence: C.-T. Yen, Institute of Zoology, National Taiwan University, 1 Roosevelt Road, Section 4, Taipei 10617, Taiwan (E-mail: ctyen@ntu.edu.tw). et al. 2005; Youell et al. 2004). The activation levels of these two areas are differentially correlated with either the pain sensation itself or the ensuing unpleasantness (Apkarian et al. 1992; Casey et al. 1994; Hofbauer et al. 2001; Hsieh et al. 1995; Rainville et al. 1997; Vogt et al. 1996).

In conscious, freely moving rats, field potentials evoked by laser-heat stimulation applied to the midtail can be recorded from the surface over the SmI (Shaw et al. 1999, 2001). Our previous studies also revealed that single SmI units recorded in behaving rats respond to noxious stimulation (Kuo and Yen 2005; Tsai et al. 2004). In anesthetized animals, SmI neurons respond to many types of sensory stimulation including pain with restricted and well-defined receptive fields (Lamour et al. 1982, 1983a,b). These data may implicate the SmI in the processing of noxious sensory information with its clear somatotopic organization.

In contrast, nociceptive neurons in the ACC have large receptive fields, sometimes covering the entire body surface (Yamamura et al. 1996). In conscious rats, ACC neurons are activated along with those in the SmI by noxious stimulation via a parallel pathway through the medial thalamus (Kuo and Yen 2005; Wang et al. 2003). Previous evidence showed the involvement of the ACC in classical fear conditioning (Kung et al. 2003; Tang et al. 2005) and the conditioned place avoidance (CPA) paradigm (Johansen and Fields 2004; Johansen et al. 2001) and implicated this area in emotional functions, particularly of anxiety and fear (Hamner et al. 1999; Phan et al. 2002).

Although the findings reviewed earlier appear to be consistent with the conjecture that the SmI and ACC are differentially involved in sensory and affective functions of pain as human data suggest, no existing study to date has dissociated the neuronal correlates of these pain functions by using single-unit recordings in animals. To address this issue, the present study was specifically designed to compare single-unit changes in the $\mathrm{SmI}$ and ACC in relation to the sensory and affective aspects of nocifensive behavior. In conscious rats subjected to tail flick and conditioned fear potentiation of startle tasks, we found that SmI neuronal activity was better correlated with the intensity of a laser stimulus evoking tail-flick responses, whereas ACC neuronal activity was better correlated with conditioned fear induced by a stimulus previously associated with a painful foot shock.

\footnotetext{
The costs of publication of this article were defrayed in part by the payment of page charges. The article must therefore be hereby marked "advertisement" in accordance with 18 U.S.C. Section 1734 solely to indicate this fact.
} 


\section{METHODS}

\section{Animals}

Experiments were performed on nine female Long-Evans rats (weight: 240-330 g). All rats were subjected to the fear-potentiated startle experiment and six of them were tested in the laser-stimulation experiment. The Animal Use and Care Committee of National Taiwan University approved all surgical and recording procedures in accordance with the Guide for the Care and Use of Laboratory Animals of the Agriculture Council of Taiwan, Republic of China.

\section{Surgery}

The surgical and implantation procedures were previously described in detail (Kuo and Yen 2005; Tsai et al. 2004). Briefly, a rat was injected with sodium pentobarbital $(50 \mathrm{mg} / \mathrm{kg}$, administered intraperitoneally) and then mounted on a stereotaxic apparatus under anesthesia. Small skull holes were made by craniotomies to expose the tissue over the cortical targets for microelectrode placement. Linear arrays of eight-channel microelectrodes made of stainless steel microwires were individually insulated with Teflon (OD, $50 \mu \mathrm{m})$. The eight microwires were evenly spaced in an array within a total span of $2 \mathrm{~mm}$ (Tsai and Yen 2003). One electrode was implanted parasagittally into the tail region of the primary sensorimotor cortex (SmI, 1-3 $\mathrm{mm}$ posterior and $2-3 \mathrm{~mm}$ lateral to the bregma, $0.5-1.5 \mathrm{~mm}$ ventral to the surface of the cortex) (Chapin and Lin 1984). The brisk multiunit responses to light touch were used to verify the receptive fields of SmI units in the individual channels. The other array of electrodes was implanted parasagittally into the ACC (1-3 mm anterior and $0.3-0.6 \mathrm{~mm}$ lateral to the bregma; $1-2 \mathrm{~mm}$ ventral to the surface of the cortex). The holes in the skull and the implanted electrodes were sealed and secured by dental cement. The rat was allowed to recover from surgery for $\geq 1 \mathrm{wk}$ before commencement of the recording and behavioral tests.

\section{Laser stimulation}

Rats were acclimatized in an acrylic chamber $(45 \times 60 \times 45 \mathrm{~cm})$ $3 \mathrm{~h} /$ day for 5 days. A rat was allowed to move freely in the chamber where stimulation was administered. Nine sessions were included in this experiment. Each session included 20 trials of infrared laser stimulation generated by a $\mathrm{CO}_{2}$ laser (medical/surgical laser, Tjing Ling \#2, National Taiwan University, 10.6- $\mu \mathrm{m}$ wavelength) (Yen et al. 1994) applied to the tail of the rat. The laser-pulse duration was $15 \mathrm{~ms}$ and the intensities varied from 1 to $9 \mathrm{~W}$, corresponding to power levels ranging from 15 to $135 \mathrm{~mJ}$. Interstimulus intervals (ISIs) were $\geq 10 \mathrm{~s}$. Sessions with different intensities were carried out in a random order. The rat was allowed a 10 -min rest between sessions. The percentage of tail-flick responses in the sessions was used as an index of the nocifensive behavior. ACC and SmI neuronal activities were recorded throughout the stimulation sessions.

\section{Training and testing of conditioned fear-potentiation of the startle reaction}

APPARATUS. A rat was trained in a $17.5 \times 9 \times 26.5-\mathrm{cm}$ acrylic chamber, the floor of which consisted of four stainless steel bars $(5$ $\mathrm{mm}$ in diameter, $1.5 \mathrm{~mm}$ apart) through which foot shocks could be delivered. The chamber was located within a sound-attenuating cubicle. A fan on the cubicle wall provided ventilation and background noise. The startle response, elicited by acoustic stimuli, was assessed by a startle apparatus (PHM-255B, Med Associates, St. Albans, VT). A noise generator controlled by a computer (Startle Reflex Software, SOF-825, Med Associates) delivered the acoustic stimuli (15-ms, $115-\mathrm{dB}$ white-noise bursts) through a speaker located $10 \mathrm{~cm}$ lateral to the chamber. A 3-s-cue light, used as the conditioned stimulus (CS), was generated by a white light-emitting diode bulb controlled by a Grass stimulator (12 V, model S48, Grass Technologies, West Warwick, RI). The bulb was $7 \mathrm{~cm}$ lateral to the animal and the illumination was about 260 lux. The unconditioned stimulus (US) was a 3-mA/8-ms foot shock produced by a Grass stimulator with an isolation unit (model S48, Grass Instruments, West Warwick, RI).

PRECONDITIONING TEST SESSION. After recovery from surgery, rats were acclimatized to the training and testing boxes in the soundattenuated cubicle $3 \mathrm{~h}$ /day for 5 days. Animals were temporarily anesthetized with halothane (4\%) to connect the head stages to the connectors implanted in the skull. At least $1 \mathrm{~h}$ elapsed before the start of a recording period. At the beginning of a preconditioning test session, there was an acclimation period of 5 min with no acoustic startle stimuli. After the acclimation period, 10 startle-eliciting stimuli (leaders) were given at 30-s ISIs. These leaders habituated the rat to the acoustic stimuli and their responses to these were not included in the statistical analysis. Following the leaders, another 30 startle trials were carried out. Visual cues of 3-s duration were applied before the acoustic startle stimuli in 15 of the trials (light-noise trials), whereas only acoustic startle stimuli were applied in the remaining trials (noise-alone trials). The light-noise trials and noise-alone trials were arranged in a random order with ISIs of $30 \mathrm{~s}$.

TRAINING. After the pretest session, rats were presented with the visual cue as the CS paired with a foot shock for fear conditioning. Rats were given 20 light-shock pairings that consisted of a 3-s flash of light and an 8-ms, 3-mA foot shock that terminated simultaneously with the light. The mean intertrial interval was $90 \mathrm{~s}$ on average (range, 60-120 s). Three sessions of training were administered $12 \mathrm{~h}$ apart.

POSTCONDITIONING TEST SESSION. In the postconditioning test session given $12 \mathrm{~h}$ after the last training trial, the procedure was identical to that in the preconditioning test session with the acclimation leaders and 30 sequentially presented testing trials (15 light-noise and 15 noise-alone trials, randomly mixed). The difference in the startle strength between the light-noise trials and noise-alone trials was used as a behavioral index of conditioned fear. Both the startle behavior and neuronal activities during the pre- and posttest sessions were recorded for analysis.

\section{Signal recording and data analysis}

The unit activities were acquired by a Multi-channel Neuronal Acquisition Processor system (MNAP, Plexon, Dallas, TX). The electrical signals passed from the headsets to the amplifiers and were band-pass filtered (spike preamp filter: $500-3,000 \mathrm{~Hz}$; field potential filter: 3-90 Hz; gain: 10,000-20,000). The acquisition of spike waveforms and real-time spike sorting was controlled by SortClient (Plexon) and the sampling rate of individual channels was $40 \mathrm{kHz}$. The waveform and timestamps of the unit during the tasks were saved for further analysis. The saved wavelet data were analyzed with a principal component analysis and resorted by the software Off-line Sorter (Plexon). Figure 1 shows an example of a unit recorded by the same microwire in the same animal for several days. Units recorded on different days were judged to be identical based on similarities of the waveform and spike height (Fig. 1). Spike train activity was analyzed using Neuroexplorer (Nex Technologies, Littleton, MA). Perievent histograms were generated with a bin size of $50 \mathrm{~ms}$ in the fear-potentiated startle experiments and $10 \mathrm{~ms}$ in the laser-stimulation experiments.

In the laser-stimulation experiment, the baseline activity was the neuronal activity in the 1-s period before laser stimulation. The spike numbers of units in the 1-s period before and after laser application were calculated in each trial of the nine intensity tests. Differences in the number of spikes from the baseline in the 20 trials of all intensity tests were compared by one-way ANOVAs. Units with a significant stimulation-intensity effect were defined as intensity-related units. 


\section{Noise alone}
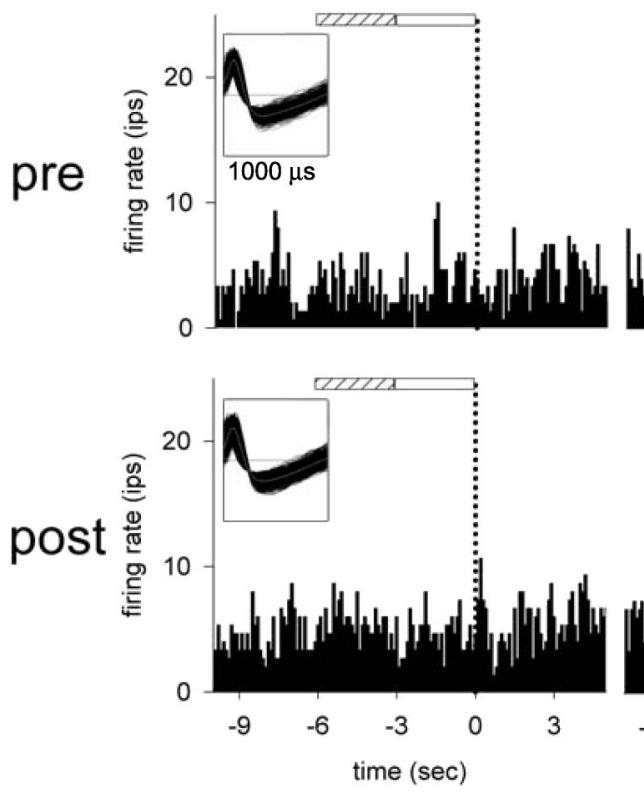

\section{Light-noise}
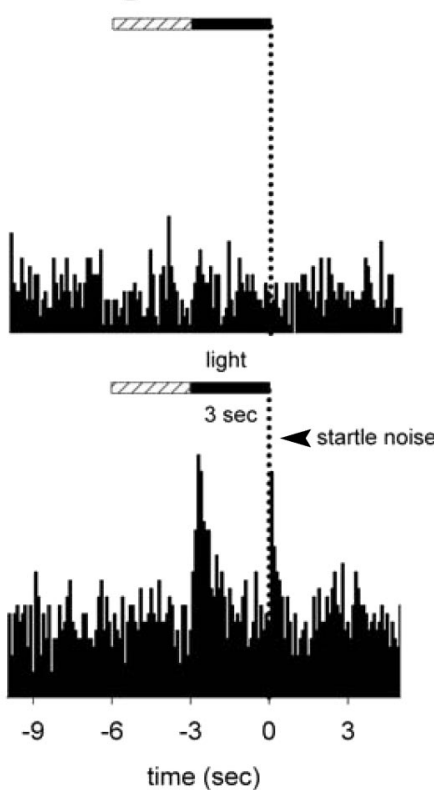

FIG. 1. A representative anterior cingulate cortical (ACC) unit recording, illustrating the method used to find light-related and conditioning-related cortical neurons. The rat underwent 2 sessions on 2 consecutive days of 30 trials of noise stimulation (at time 0 indicated by the vertical dotted lines), with the conditioned-stimulus/unconditioned-stimulus (CS-US) training performed between sessions. In half of the trials, a loud noise was preceded by a 3-s light (solid bars, light-noise trials); in the other 15 trials, only noise was presented (open bars, noisealone trials). The perievent histograms shown here represent the average activities (impulses per second [ips]) of this unit in the following 4 conditions: noise-alone/preconditioning, lightnoise/preconditioning, noise-alone/postconditioning, and lightnoise/postconditioning in 50-ms bins. For each trial, the difference in the number of spikes between the 3-s test period vs. the 3 -s baseline period (hatched bar) was calculated. Two-way ANOVAs followed by pairwise comparisons were performed on the 4 sets of values to test for light significance, conditioning significance, and light and conditioning significance. Similarly, one-way ANOVA was used to find intensity-related units in the laser-heat stimulation experiment. The superimposed waveforms (of 1-ms duration) of all spikes recorded are shown in the insets in the left corner of each session. Note the stability of the recording throughout the 2 days.
Ensemble neuronal activities were obtained by linearly summing the multiple single-unit data from one animal. Ensemble activities of the intensity-related SmI neurons from channels with receptive fields in the tail and hindlimb and the intensity-related ACC neurons were calculated separately. The baseline activity of ensemble neurons in the SmI and ACC were calculated. The fast and slow components of the neuronal activities were defined by the average firing rate of ensemble neuronal activity during the 10 - to 140 - and 150 - to 600 -ms periods, respectively, after laser stimulation (Kuo and Yen 2005). A linear regression was used for both the short- and long-latency response components in the SmI and ACC against the intensity of laser stimulation to obtain the slope of the regression line. Nocifensive behavior was evaluated by the ratio of the number of tail-flick responses to stimulation times in each session.

In the conditioned-fear potentiation of the startle experiment, the average startle strength in noise-alone trials was designated $100 \%$. The perievent (acoustic stimuli) histograms of the SmI and ACC units were separately analyzed. The 3 -s period before the acoustic stimulus was designated the prestartle phase (white bars and black bars in Fig. 1) and the 3-s period before the prestartle phase was designated the pretrial control phase (slashed bars in Fig. 1). The difference between the number of spikes during the prestartle phase and that during the pretrial control phase was calculated for individual trials. These values of activity change calculated from 15 light-noise and 15 noise-alone trials in the pre- and the postconditioning tests were subjected to two-way (trial type $\times$ conditioning session) ANOVAs. Units showing significant effects in the factor of trial type, conditioning session, or the interaction between the two were defined, respectively, as lightrelated, conditioning-related, and light-and-conditioning-related units. The average firing rates in the pretrial control phase were designated $100 \%$.

\section{Statistic analysis}

The neuronal responses of the SmI and ACC in the laser-stimulation task and the startle behavior and neuronal activities of both areas during the fear-potentiated startle task were compared by two-way ANOVAs with a repeated-measure design. Post hoc comparisons were made with the Bonferroni method. The slopes of the regression lines for the unit activity-intensity responses in both brain areas were compared by paired $t$-tests. Data are expressed as the mean $\pm \mathrm{SE}$ if not otherwise denoted.

\section{Identification of recording sites}

At the end of the experiments, electrical lesions $(50 \mu \mathrm{A}, 30 \mathrm{~s})$ or deposits of ferric ions $(5 \mu \mathrm{A}, 30 \mathrm{~s})$ were made through selected electrodes of the microelectrode array. An animal was perfused intracardially with saline followed by $10 \%$ formalin (with $1 \%$ potassium ferrocyanide for the iron deposit). The brain was removed and postfixed in the perfusion fluid. The frozen brain was serially sectioned at $100 \mu \mathrm{m}$ with a sliding microtome. Sections were stained with cresyl violet. Positions of the electrode tips were confirmed by

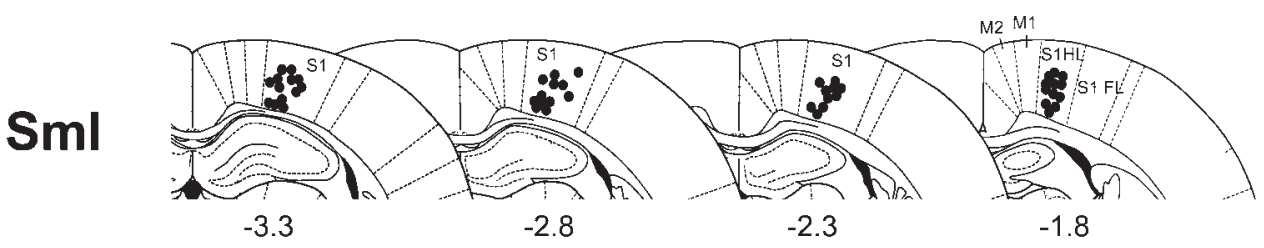

$-2.3$

$$
-1.8
$$

\section{ACC}

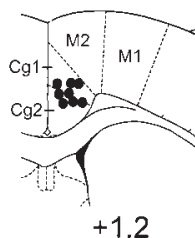

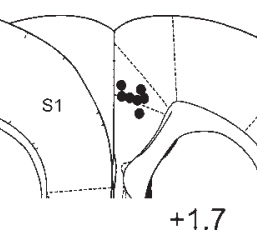

$+1.7$

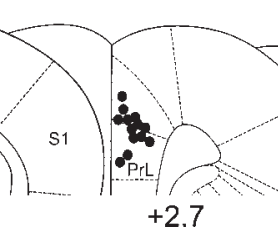

$+2.7$

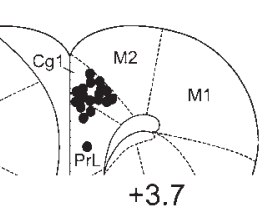

$1 \mathrm{~mm}$
FIG. 2. Distribution of recording sites. The top panel shows the recording sites in the primary sensorimotor cortex $(\mathrm{SmI})$; the bottom panel shows the recording sites in the ACC. Locations of the tips of the recording electrodes were identified by histological methods and are represented as dots on a standard atlas (Paxinos and Watson 1998). Numerals are the anterior-posterior relationship of the section (in millimeters) to the bregma. $\mathrm{Cg} 1 / \mathrm{Cg} 2$, cingulate cortex $1 / 2$; M1/ M2, primary/secondary motor cortex; PrL, prelimbic cortex; S1, primary somatosensory cortex; FL/HL, forelimb/hindlimb area. 
A Sml
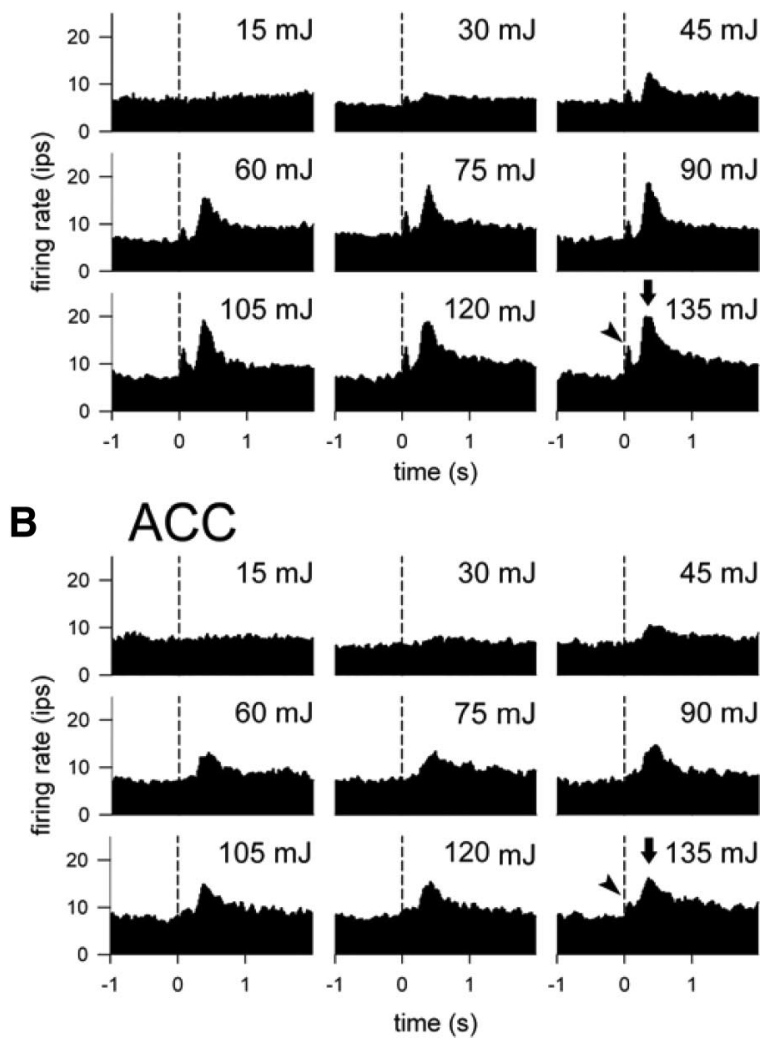

FIG. 3. Peristimulation histograms of ensemble unit activity in response to different intensities of laser-heat irradiation of the middle portion of the tail. A: $59 \mathrm{SmI}$ intensity-related units. $B: 31 \mathrm{ACC}$ intensity-related units. Note the short-latency (arrowhead) and long-latency (arrow) responses in both the SmI and ACC at high stimulation intensities. Bin size: $10 \mathrm{~ms}$. The dashed line indicates the onset time of the 15-ms laser-heat pulse.

microscopic observations. Figure 2 shows the distribution of all electrode tips in the SmI and ACC.

\section{R E S ULT S}

\section{Behavioral and neural responses to laser-heat stimulation}

The threshold intensity that elicited a tail-flick response was about $30 \mathrm{~mJ}$ and the relative frequency of the flick response reached its maximum at $90 \mathrm{~mJ}$. In total, $118 \mathrm{ACC}$ and $85 \mathrm{SmI}$ units recorded throughout the experiment were analyzed. Consistent with our previous findings (Kuo and Yen 2005), two components were detected in the SmI and ACC neuronal responses: a short-latency component $(<150 \mathrm{~ms})$ and a longlatency component (300-500 ms) (Fig. 3). The evoked singleunit activities were analyzed by one-way ANOVA to determine the significance of the effect of stimulation intensity. The activities of $59 \mathrm{SmI}(69.4 \%)$ and 31 ACC units $(26.3 \%)$ significantly varied with the stimulation intensity. The frequency of stimulation intensity-related units was significantly higher in the SmI than that in the $\operatorname{ACC}\left(\chi^{2}=35.533\right.$, df $=1$, $P<0.01$, Table 1).

ACC and SmI units were both activated by high-intensity stimulation. A noticeable response in the SmI was elicited by 30-mJ laser stimulation, but a higher intensity was needed to evoke an observable response in the ACC (Figs. 3 and 4). The neuronal responses of both components were compared quan-
TABLE 1. Number and percentage of single units in the ACC and SmI, whose activities were significantly changed by intensity

\begin{tabular}{lrrrrr}
\hline \hline & \multicolumn{2}{c}{ ACC } & & \multicolumn{2}{c}{ SmI } \\
\cline { 2 - 3 } \cline { 5 - 6 } & $n$ & Percentage & & $n$ & Percentage \\
\hline Significant & 31 & $26.3 \%$ & & 59 & $69.4 \%$ \\
Not significant & 87 & $73.7 \%$ & & 26 & $30.6 \%$ \\
$\quad$ Total & 118 & & & 85 & \\
\hline
\end{tabular}

ACC, anterior cingulate cortex; SmI, primary sensorimotor cortex.

titatively. Figure $4, A$ and $B$ shows a rise in SmI and ACC ensemble neuronal responses in the short- and long-latency components with increased stimulation intensities. The frequency ratio of the tail-flick responses of the rats increased with the stimulus intensity (Fig. 4C). At all suprathreshold
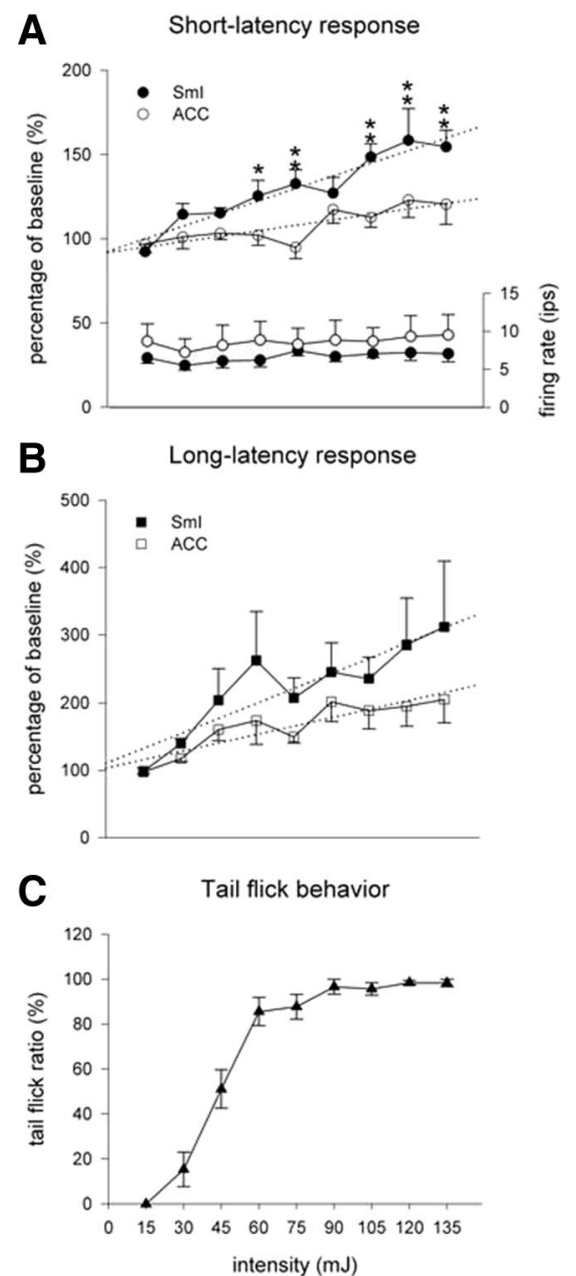

FIG. 4. Neuronal and behavior responses to laser-heat stimulation of different intensities to the midtail. ACC and SmI short-latency $(A)$ and longlatency $(B)$ components were analyzed separately. At higher intensities, the short-latency responses in the SmI were significantly stronger than those in the ACC. $C$ : the tail flick ratio increased with a stronger stimulation intensity. Solid symbols, SmI units; open symbols, ACC units. The graphs in the bottom of $A$ show the baseline firing rates of SmI (solid) and ACC (open) units. No difference was found between the baseline activities. $* P<0.05$, $* * P<0.01$, compared with the ACC group. The dotted lines indicate the linear regressions of the neuronal responses to the stimulation intensities. 


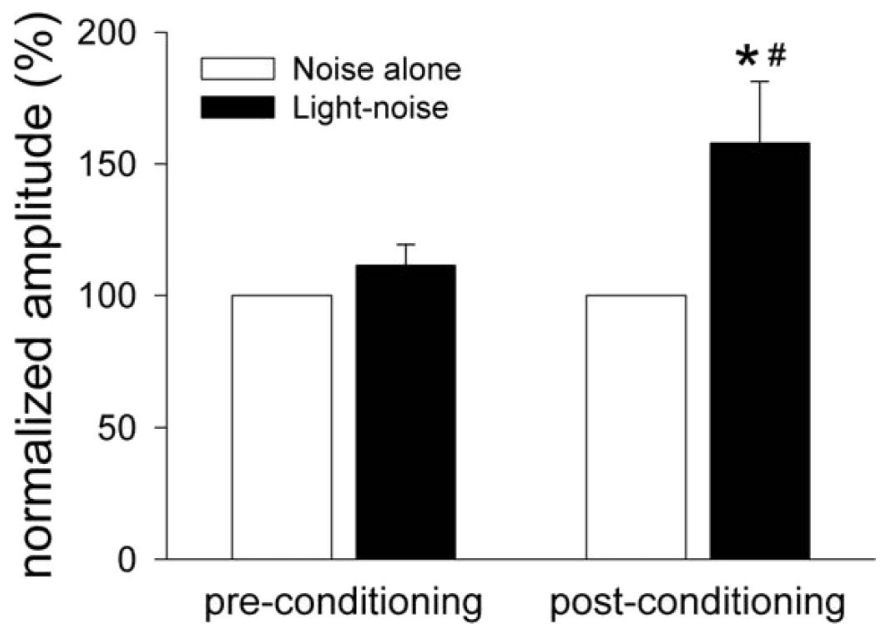

FIG. 5. Fear-potentiated startle responses as shown by a comparison of the relative amplitudes of the startle evoked by the loud noise in the 4 conditions. Before training, the average startle strengths in the light-noise trials and noise-alone trials did not significantly differ. After training, the average startle strength in the light-noise trials was significantly stronger. The normalized startle strength is the ratio in percentage of the averaged amplitude of vibration in the noise-alone trials of the same session. $* P<0.05$, compared with the noise-alone in the postconditioning session; ${ }^{\#} P<0.05$, compared with the light-noise condition in the preconditioning session.

intensities, short- and long-latency components of SmI units showed stronger responses than did ACC units. In the shortlatency component, two-way ANOVA revealed a significant effect of area $[F(1,10)=47.256, P<0.01, n=6]$ in which the difference between $\mathrm{SmI}$ and ACC units at intensities $>60 \mathrm{~mJ}$ was significant with the post hoc comparison $(P<0.05$ or $0.01)$ and there were both a significant effect of intensities $[F(8,80)=4.708, P<0.01]$ and a significant interaction effect of area $\times$ intensity $[F(8,80)=2.985, P<0.05]$. A linear regression analysis was performed between the laser-stimulation intensity and short-latency neuronal response. The average slope of the regression line for the SmI was significantly steeper than that of the ACC $(0.50 \pm 0.12$ vs. $0.22 \pm 0.11, P<$ $0.05)$. For the long-latency response component, two-way ANOVA revealed a significant effect of intensity $[F(8,80)=$ 4.31, $P<0.01]$. The average slope of the regression line for the SmI appeared to be steeper than that for the ACC (1.49 \pm 0.61 vs. $0.83 \pm 0.25)$, but the difference failed to reach statistical significance. Taken together, these results suggest that a higher percentage of responsive units and better intensity-dependent unit activities were recorded in the SmI than in the ACC.

\section{Behavioral changes during the fear-potentiated startle test}

The average startle amplitudes for the light-noise trials and noise-alone trials in the pre- and postconditioning tests were analyzed by two-way ANOVA with a repeated-measures design. The analysis showed significant effects for trial types $[F(1,16)=5.70, P<0.05, n=9]$, test sessions $[F(1,16)=$ 5.92, $P<0.05]$, and the interaction between the two $[F(1,16)=5.92, P<0.05]$. The post hoc comparison revealed a significant difference between the light-noise and noisealone trials in the postconditioning test and a significant difference in the light-noise trial between the pre- and postconditioning tests $(P<0.01$, Fig. 5). These results confirmed that the training procedures in this study successfully produced conditioned fear to potentiate startle responses, consistent with previous reports (Davis 1986).

\section{$A C C$ and SmI neuronal activity changes during the fear-potentiated startle task}

In all, 142 single units in the ACC and 102 units with tail or limb receptive fields in the SmI were held throughout the procedure. Changes in unit activities in 15 light-noise trials and 15 noise-alone trials of the pre- and postconditioning tests were compared by two-way ANOVA. Sixteen ACC units $(11.3 \%)$ and 9 SmI units $(8.8 \%)$ showed significantly altered activity by conditioning (conditioning-related units). Twentyeight ACC units (19.7\%) and 18 SmI units (17.7\%) showed significantly different activity between the light-noise and noise-alone trials (light-related units). In addition, 17 ACC $(12.0 \%)$ and $5 \mathrm{SmI}$ units $(4.9 \%)$ showed significantly altered activity by both the trial type and conditioning session (lightand-conditioning-related units): $71 \%$ of ACC units and $75 \%$ of SmI units, which showed higher activities in the light-noise trials than in the noise-alone trials, were classified as excitatory units. The other responsive units (29\% of ACC and $25 \%$ of SmI responsive units), which showed lower activities in the light-noise trials than in the noise-alone trials, were classified as inhibitory units. Distribution of the excitatory and the inhibitory types in the ACC and SmI is listed in Table 2. Distributions of responsive units in the ACC and SmI significantly differed as assessed by a $2 \times 2 \chi^{2}$ test $\left(\chi^{2}=4.111\right.$, $P<0.05)$.

A representative example of an excitatory ACC unit is shown in Fig. 6A. In the preconditioning sessions, the firing rates of these units were not affected irrespective of whether a visual cue was presented. After the CS-US pairing, no obvious change in the firing rate was detected in the noise-alone trials.

TABLE 2. Number and percentage of single units in the ACC and SmI whose activity significantly changed by light, by association learning (conditioning), or by both

\begin{tabular}{|c|c|c|c|c|c|c|c|c|}
\hline & \multicolumn{4}{|c|}{ ACC } & \multicolumn{4}{|c|}{ SmI } \\
\hline & $\mathrm{E}$ & I & $n$ & Percentage & $\mathrm{E}$ & I & $n$ & Percentage \\
\hline \multicolumn{9}{|l|}{ Significant } \\
\hline Conditioning only & 8 & 8 & 16 & $11.3 \%$ & 5 & 4 & 9 & $8.8 \%$ \\
\hline Light only & 22 & 6 & 28 & $19.7 \%$ & 15 & 3 & 18 & $17.7 \%$ \\
\hline Light and conditioning & 13 & 4 & 17 & $12.0 \%$ & 4 & 1 & 5 & $4.9 \%$ \\
\hline Not significant & & & 81 & $57.0 \%$ & & & 70 & $68.6 \%$ \\
\hline Total & & & 142 & & & & 102 & \\
\hline
\end{tabular}

E, excitatory units; I, inhibitory units. 
A

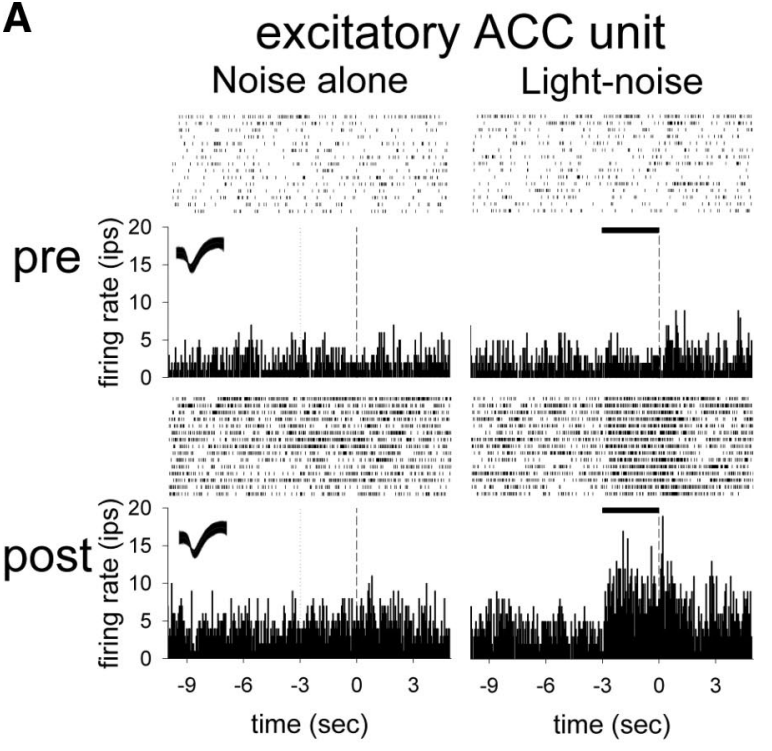

B

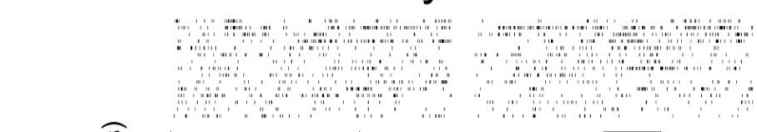

pre
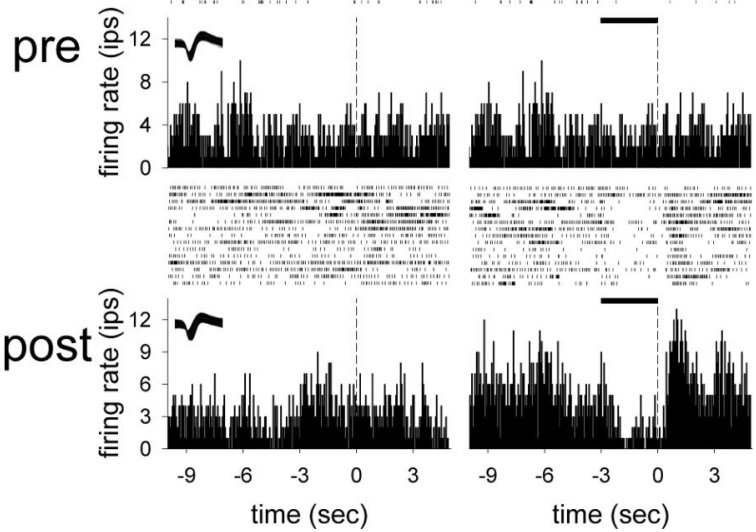

FIG. 6. Representative examples of excitatory $(A)$ and inhibitory $(B)$ ACC units. $A$ and $B$ : perievent raster plots of 15 trials each and their average perievent histograms of the 4 conditions: noise-alone/preconditioning, lightnoise/preconditioning, noise-alone/postconditioning, and light-noise/postconditioning. Note that drastic changes in the single-unit and ACC ensemble activities occurred only in the 3-s test period with light cue (solid bars) of the postconditioning session. Bin length: $50 \mathrm{~ms}$. Superimposed 1-ms spike waveforms are shown in the left corner of the unit histograms.

However, these units displayed lasting enhancement of the firing rate in the light-noise trials during the visual-cue period. Figure $6 B$ shows a representative example of the inhibitory units, the firing rate of which decreased during the visual-cue periods in the light-noise trial after training. Population perievent histograms of all light-responsive neurons are shown in Fig. 7. The ACC ensemble activity included the 22 excitatory light-related units and 13 excitatory light-and-conditioning-related units; the SmI ensemble activities were from the 15 excitatory light-related units and 4 excitatory light-and-conditioning-related units (Table 2). A clear learning effect from the conditioning process was seen in both the ACC and SmI.

We quantitatively analyzed the activity changes of responsive units in the three categories. Changes in the average firing rate from the baseline of ACC and SmI units in the 3-s prestartle phase were compared between the noise-alone and light-noise trials and between pre- and postconditioning sessions. In the light-and-conditioning-related ACC units, twoway ANOVA revealed a significant effect of test session $[F(1,16)=7.716, P<0.05, n=17]$ and the interaction between trial and test session $[F(1,16)=6.269, P<0.05]$. With post hoc comparisons, there was no difference in the changes in firing rates between the light-noise and noisealone trials $(30.7 \pm 13.5$ vs. $34.3 \pm 14.2 \%, P>0.05)$ in the preconditioning sessions, so the visual cues did not induce significant changes in unit activity before conditioning. In the postconditioning session, activities of ACC units significantly changed in the visual-cue presentation period of the light-noise trials $(144.0 \pm 49.4 \%)$ compared with those in the noise-alone trials $(14.7 \pm 5.6 \%, P<0.01)$. In the conditioning-related ACC units, two-way ANOVA revealed a significant effect of test session $[F(1,15)=12.274, P<0.01, n=16]$. Firing rates of ACC units did not significantly change in the light-noise or noise-alone trials in the preconditioning $(14.0 \pm 2.2$ vs. $25.8 \pm$ $4.7 \%, P>0.05)$ and postconditioning $(26.3 \pm 5.5$ vs. $38.4 \pm$ $11.4 \%, P>0.05)$ sessions. In light-related ACC units, twoway ANOVA revealed a significant effect of trial $[F(1,27)=$ 33.704, $P<0.01, n=28]$. With post hoc comparisons, changes in ACC units in the light-noise trials were signifi-

\section{A}

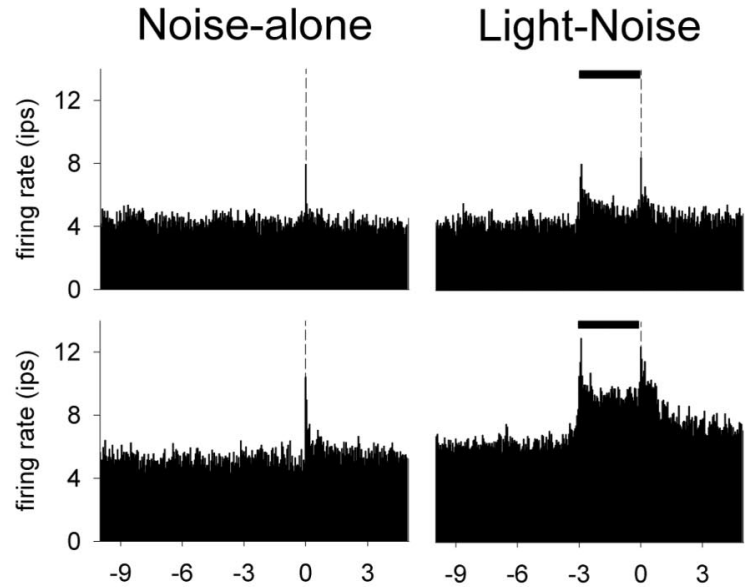

B
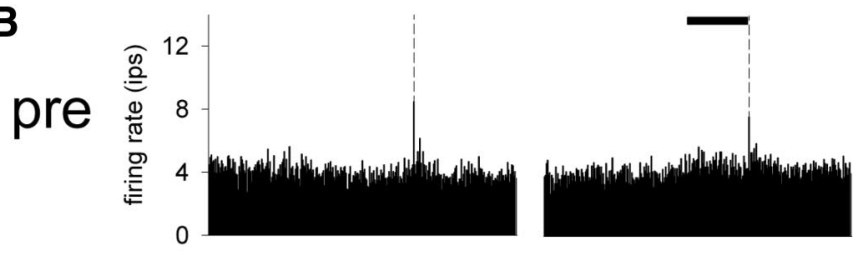

post
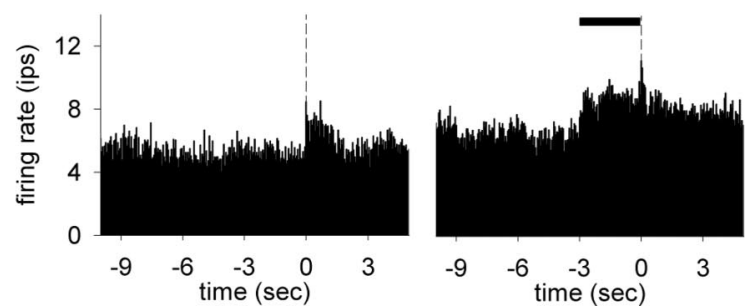

FIG. 7. Perievent histograms of averaged activity from $(A) 35$ excitatory ACC unit and (B) 19 excitatory SmI units, of the 4 conditions: noise-alone/ preconditioning, light-noise/preconditioning, noise-alone/postconditioning, and light-noise/postconditioning. These excitatory units included both the light-related only and the light-and-conditioning-related types. Note enhanced light responsiveness in both ACC and SmI units after conditioning. 

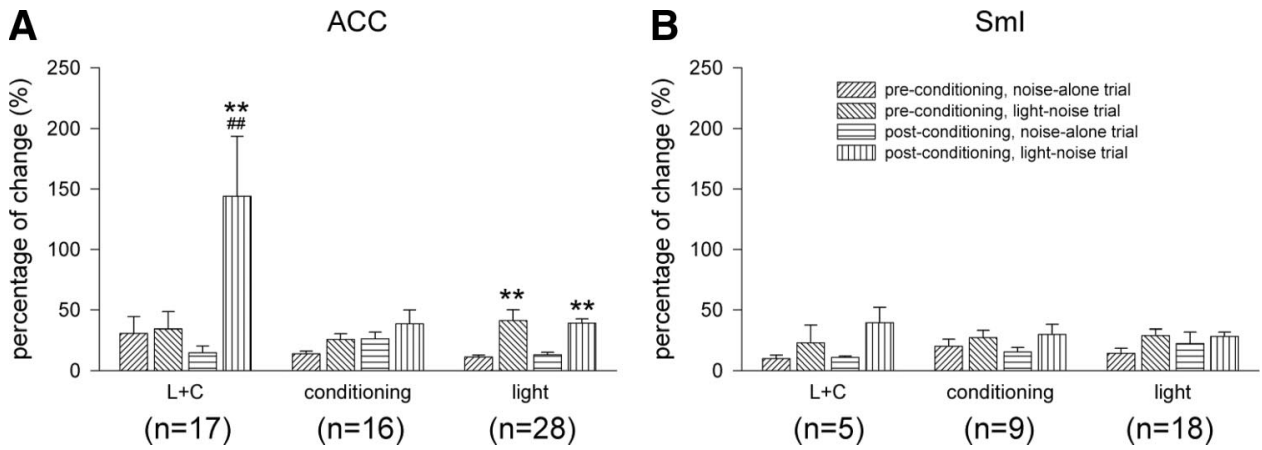

FIG. 8. Comparison of unit activity changes in the 3-s test period in the ACC and SmI. The magnitudes of change of both excitatory and inhibitory units were included. Note significant changes were observed only in the ACC. L+C, light-and-conditioning-related units; $* * P<$ 0.01 , compared with the noise-alone condition, ${ }^{\# \#} P<0.01$, compared with the same group in the preconditioning session. cantly higher than those in the noise-alone trials in the preconditioning $(11.2 \pm 1.5$ vs. $41.2 \pm 8.6 \%, P<0.01)$ and postconditioning sessions $(13.1 \pm 2.0$ vs. $38.9 \pm 3.7 \%, P<0.01)$ (Fig. 8A).

The two-way ANOVA showed no significant effect in lightand-conditioning-related SmI units (10.0 \pm 2.8 vs. $23.1 \pm$ $14.1 \%$ in the preconditioning session; $11.0 \pm 1.0$ vs. $39.2 \pm$ $12.8 \%$ in the preconditioning session). In conditioning-related SmI units, two-way ANOVA showed a significant effect of test session $[F(1,8)=15.796, P<0.01, n=9]$. Post hoc comparisons showed no significant difference between changes in SmI unit activities in the light-noise and noise-alone trials before conditioning $(20.1 \pm 6.0$ vs. $29.0 \pm 5.1 \%, P>0.05)$ or after conditioning (15.6 \pm 3.5 vs. $30.0 \pm 8.0 \%, P>0.05)$. Two-way ANOVA showed no significant effect for lightrelated SmI units $(14.2 \pm 4.2$ vs. $29.0 \pm 5.1 \%$ in the preconditioning session; $22.4 \pm 9.3$ vs. $28.4 \pm 3.4 \%$ in the preconditioning session) (Fig. $8 B$ ). Taken together, these results suggest that changes in ACC unit activities were forged during the conditioning process and the activity change in ACC units in this task was higher than that of SmI units.

\section{I S C U S S I O N}

This study compared neuronal responses in the SmI and ACC for two different tasks that probed different functional aspects of pain. The laser-irradiation task assessed the nociceptive coding ability, whereas the fear-potentiated startle task assessed pain-induced fear conditioned to a visual cue. Our major findings are summarized as follows. 1) Both ACC and SmI unit responses increased with stronger noxious stimuli, but the coding ability of the SmI units was significantly better than that of ACC units. 2) Many ACC and SmI units showed significantly enhanced or decreased activity in anticipation of a painful shock after conditioning. Compared with the SmI, a significantly higher percentage of ACC units showed changes in activity during the fear-potentiated startle task and ACC unit activities showed a significantly greater change.

Noxious information is coded by multiple brain channels. Two major parallel pathways for processing pain information in the brain have been proposed (Albe-Fessard et al. 1985; Craig 2005). The lateral pathway projects from the ventroposterior thalamic nuclei to the SmI, whereas the medial pathway projects from the medial thalamic nuclei to the ACC. In congruence with previous studies, the present study found that many neurons in the ACC and SmI respond to noxious laserheat stimulation of the tail (Kuo and Yen 2005; Tsai et al. 2004). However, the responses in these two regions did not appear to be the same. Our previous study showed that SmI responses were faster and more prominent and showed up at a lower intensity in conscious behaving rats (Kuo and Yen 2005). Furthermore, the present findings revealed that a higher percentage of SmI neurons was intensity related and the ensemble activity of these intensity-related SmI neurons had steeper response slopes along with an elevation of stimulation intensity than those in the ACC of the same rat.

Thus the present data, together with existing information, suggest that the SmI has better sensory-discriminating capabilities for different stimulation intensities, especially toward shorter-latency responses. Brain imaging studies in human subjects have also implicated the SmI as the major site for stimulus-intensity coding (Hofbauer et al. 2001; Porro et al. 1998; Rainville et al. 1997; San Pedro et al. 1998). Our data showed that ACC neurons were also activated by laser stimulation, although to a lesser extent, and were less sensitive to intensity variations than were SmI neurons. Neurons in the ACC with nociceptive-specific responses have been found in rodents, rabbits, monkeys, and humans (Hutchison et al. 1999; Koyama et al. 1998; Sikes and Vogt 1992). These findings are consistent with those showing that ACC lesions also change their sensitivity to electric shocks in a startle task (Chen et al. 2000), block mechanical hypersensitivity in animals with L5 spinal nerve ligation, and significantly decrease escape/avoidance behavior (LaGraize et al. 2004). Lesions of the ACC or a disturbance to the cingulum bundle reduced inflammatory pain behavior in rats (Donahue et al. 2001; Fuchs et al. 1996; Vaccarino and Melzack 1989).

This study also compared SmI and ACC neuronal responses in an emotion-evoking context previously associated with noxious experiences in a fear-potentiated startle task, a wellestablished behavioral model for investigating fear and anxiety (Davis 1986, 2006; Hamm and Weike 2005; Miserendino et al. 1990; Sananes and Davis 1992; Shi and Davis 1999; Tischler and Davis 1983). The enhancement of startle strengths in the postconditioning session in this study (Fig. 5) confirmed the success of fear induction by the CS-US pairing procedure in this study. Our results also showed that forebrain neuronal responses modeled behavioral changes during learning. After conditioning, the activities of many ACC and SmI neurons changed in the presence of the CS. In our study, both ACC and SmI neurons showed significant unit-activity changes when the CS was presented in the postconditioning test, in contrast to what appeared in the preconditioning test. These results suggest that changes in unit activities were forged by the CS-US pairing procedure rather than the arousing effect of visual cues. 
Our results showed that the unit activities of a higher percentage of ACC neurons than SmI ones changed during the fear-potentiated startle task, suggesting the importance of the $\mathrm{ACC}$ in the fear-conditioning paradigm. In monkeys, single neuronal activities in the ACC were altered, when they performed discriminative pain-avoidance and reward tasks. Those results indicated that anterior cingulate neurons are involved in the anticipation of and selection of a response to imminent events (Koyama et al. 2001). Previous studies also reported cortical training-induced neural activity during discriminative avoidance learning in rabbits, in which ACC units showed significant changes in firing rates to a foot-shock predictive conditional stimulus $(\mathrm{CS}+)$, but not to a safety-predictive conditional stimulus (CS-) (Duvel et al. 2001; Kubota et al. 1996). These results are also consistent with those from human imaging studies showing activation of the ACC after contextual and cued-fear conditioning (Marschner et al. 2008).

The present study did not address the issue of whether the ACC plays a causal role in fear conditioning. Previous findings showed that in a two-phase inhibitory avoidance task (Liang 1999), intra-ACC infusion of oxotremorine immediately after shock training, but not after context training, impaired retention, suggesting involvement of the ACC in processing shockinduced fear associations (Malin and McGaugh 2006). Interactions between the ACC and amygdala, a structure widely implicated in emotional learning, have also been reported (Bissiere et al. 2008; Malin et al. 2007). In congruence with the findings that ACC lesions disrupt fear conditioning, activation of the ACC is sufficient to serve as an aversive signal to induce fear conditioning (Gabriel et al. 1991; Kung et al. 2003; Tang et al. 2005) and conditioned place avoidance (Johansen and Fields 2004; Johansen et al. 2001). These data suggest that the ACC is involved in generating fear by an otherwise neutral stimulation associated with pain. This conjecture is consistent with primate data showing that ACC lesions impaired avoidance behavior elicited by noxious somatic stimuli in monkeys (Koyama et al. 2000) and that a cingulotomy is effective in relieving intractable chronic pain in human beings (Hassenbusch et al. 1990; Pillay and Hassenbusch 1992; Wong et al. 1997) because such surgery rendered the pain less bothersome but by no means eliminated the perception of it (Foltz and White Jr 1962).

In our study, the activities of some SmI neurons also changed in response to a visual cue anticipating an electric shock after associative training, although to a less-prominent extent than that in the ACC. Many sensory cortices, including the primary visual, auditory, and somatosensory ones, change their activities in response to behavioral tasks involving perceptual memory (Buonomano and Merzenich 1998), an effect presumably reflecting an increase in discriminative sensitivity to a relevant stimulus critical for successful learning in various tasks (Weinberger 2004). It was indicated that learning and experience can modulate the sensory cortex. Cortical reorganization was observed in experiments of amputation (Merzenich et al. 1984), retinal lesions (Kaas et al. 1990), and sensory-discrimination training (Recanzone et al. 1992) in which cortical reorganization was induced and plasticity of the cortex was evident. Receptive field plasticity was also observed with classical conditioning (Bakin et al. 1996) and frequency-discrimination training (Recanzone et al. 1993). Those studies illustrate that the sensory cortex can be modu- lated by learning and experience and has a potential role in memory.

In summary, we observed differential involvements of the SmI and ACC in laser stimulation and conditioned-fear potentiation of a startle task, respectively. The $\mathrm{SmI}$ showed better graded responses to stimuli with various intensities, thus possibly contributing more to the sensory-discrimination function. The activities of a higher percentage of the ACC neurons changed with the acquisition of the conditioned-fear task and the magnitude of the activity change was stronger. The ACC thus contributes more to affective function. On the other hand, because ACC neuronal activity also responded to intensity changes and many SmI neuronal activities also changed in the fear-potentiated startle task, the segregation of functions cannot be absolute but, instead, a matter of degree.

\section{A C K N OW LED G MENTS}

We thank Dr. Deh-Yow Chen for assistance in setting up procedures for the behavioral task.

\section{G R A N T S}

This work was supported by National Science Council, Taiwan Grant NSC93-2311-B-002-012.

\section{REFERENCES}

Albe-Fessard D, Berkley KJ, Kruger L, Ralston HJ, Willis WDJ. Diencephalic mechanisms of pain sensation. Brain Res 356: 217-296, 1985.

Apkarian AV, Bushnell MC, Treede RD, Zubieta JK. Human brain mechanisms of pain perception and regulation in health and disease. Eur J Pain 9: 463-484, 2005

Apkarian AV, Stea RA, Manglos SH, Szeverenyi NM, King RB, Thomas FD. Persistent pain inhibits contralateral somatosensory cortical activity in humans. Neurosci Lett 140: 141-147, 1992.

Bakin JS, South DA, Weinberger NM. Induction of receptive field plasticity in the auditory cortex of the guinea pig during instrumental avoidance conditioning. Behav Neurosci 110: 905-913, 1996.

Bingel U, Lorenz J, Glauche V, Knab R, Glascher J, Weiller C, Buchel C. Somatotopic organization of human somatosensory cortices for pain: a single trial fMRI study. Neuroimage 23: 224-232, 2004.

Bingel U, Quante M, Knab R, Bromm B, Weiller C, Buchel C. Single trial fMRI reveals significant contralateral bias in responses to laser pain within thalamus and somatosensory cortices. Neuroimage 18: 740-748, 2003.

Bissiere S, Plachta N, Hoyer D, McAllister KH, Olpe HR, Grace AA, Cryan JF. The rostral anterior cingulate cortex modulates the efficiency of amygdala-dependent fear learning. Biol Psychiatry 63: 821-831, 2008.

Buffington AL, Hanlon CA, McKeown MJ. Acute and persistent pain modulation of attention-related anterior cingulate fMRI activations. Pain 113: 172-184, 2005.

Buonomano DV, Merzenich MM. Cortical plasticity: from synapses to maps. Апnи Rev Neurosci 23: 1-38, 1998.

Casey KL, Minoshima S, Berger KL, Koeppe RA, Morrow TJ, Frey KA. Positron emission tomographic analysis of cerebral structures activated specifically by repetitive noxious heat stimuli. $J$ Neurophysiol 71: 802-807, 1994.

Chapin JK, Lin CS. Mapping the body representation in the SmI cortex of anesthetized and awake rats. J Comp Neurol 229: 199-213, 1984.

Chen DY, Ho SH, Liang KC. Startle responses to electric shocks: measurement of shock sensitivity and effects of morphine, buspirone and brain lesions. Chin J Physiol 43: 35-47, 2000.

Chen JI, Ha B, Bushnell MC, Pike B, Duncan GH. Differentiating noxiousand innocuous-related activation of human somatosensory cortices using temporal analysis of fMRI. J Neurophysiol 88: 464-474, 2002.

Craig AD. Forebrain emotional asymmetry: a neuroanatomical basis? Trends Cogn Sci 9: 566-571, 2005.

Davis M. Pharmacological and anatomical analysis of fear conditioning using the fear-potentiated startle paradigm. Behav Neurosci 100: 814-824, 1986.

Davis M. Neural systems involved in fear and anxiety measured with fearpotentiated startle. Am Psychol 61: 741-756, 2006. 
Donahue RR, LaGraize SC, Fuchs PN. Electrolytic lesion of the anterior cingulate cortex decreases inflammatory, but not neuropathic nociceptive behavior in rats. Brain Res 897: 131-138, 2001.

Duvel AD, Smith DM, Talk A, Gabriel M. Medial geniculate, amygdalar and cingulate cortical training-induced neuronal activity during discriminative avoidance learning in rabbits with auditory cortical lesions. $J$ Neurosci 21: 3271-3281, 2001.

Foltz EL, White LE Jr. Pain "relief" by frontal cingulumotomy. J Neurosurg 19: 89-100, 1962

Fuchs PN, Balinsky M, Melzack R. Electrical stimulation of the cingulum bundle and surrounding cortical tissue reduces formalin-test pain in the rat. Brain Res 743: 116-123, 1996.

Gabriel M, Kubota Y, Sparenborg S, Straube K, Vogt BA. Effects of cingulate cortical lesions on avoidance learning and training-induced unit activity in rabbits. Exp Brain Res 86: 585-600, 1991.

Hamm AO, Weike AI. The neuropsychology of fear learning and fear regulation. Int J Psychophysiol 57: 5-14, 2005.

Hamner MB, Lorberbaum JP, George MS. Potential role of the anterior cingulate cortex in PTSD: review and hypothesis. Depress Anxiety 9: 1-14, 1999.

Hassenbusch SJ, Pillay PK, Barnett GH. Radiofrequency cingulotomy for intractable cancer pain using stereotaxis guided by magnetic resonance imaging. Neurosurgery 27: 220-223, 1990.

Hofbauer RK, Rainville P, Duncan GH, Bushnell MC. Cortical representation of the sensory dimension of pain. J Neurophysiol 86: 402-411, 2001

Hsieh JC, Belfrage M, Stone-Elander S, Hansson P, Ingvar M. Central representation of chronic ongoing neuropathic pain studied by positron emission tomography. Pain 63: 225-236, 1995.

Hutchison WD, Davis KD, Lozano AM, Tasker RR, Dostrovsky JO. Pain-related neurons in the human cingulate cortex. Nat Neurosci 2: 403 405, 1999.

Johansen JP, Fields HL. Glutamatergic activation of anterior cingulate cortex produces an aversive teaching signal. Nat Neurosci 7: 398-403, 2004.

Johansen JP, Fields HL, Manning BH. The affective component of pain in rodents: direct evidence for a contribution of the anterior cingulate cortex Proc Natl Acad Sci USA 98: 8077-8082, 2001.

Kaas JH, Krubitzer LA, Chino YM, Langston AL, Polley EH, Blair N. Reorganization of retinotopic cortical maps in adult mammals after lesions of the retina. Science 248: 229-231, 1990.

Koyama T, Kato K, Mikami A. During pain-avoidance neurons activated in the macaque anterior cingulate and caudate. Neurosci Lett 283: 17-20, 2000.

Koyama T, Kato K, Tanaka YZ, Mikami A. Anterior cingulate activity during pain-avoidance and reward tasks in monkeys. Neurosci Res 39: 421-430, 2001.

Koyama T, McHaffie JG, Laurienti PJ, Coghill RC. The subjective experience of pain: where expectations become reality. Proc Natl Acad Sci USA 102: 12950-12955, 2005.

Koyama T, Tanaka YZ, Mikami A. Nociceptive neurons in the macaque anterior cingulate activate during anticipation of pain. Neuroreport 9: 2663-2667, 1998.

Kubota Y, Wolske M, Poremba A, Kang E, Gabriel M. Stimulus-related and movement-related single-unit activity in rabbit cingulate cortex and limbic thalamus during performance of discriminative avoidance behavior. Brain Res 721: 22-38, 1996.

Kung JC, Su NM, Fan RJ, Chai SC, Shyu BC. Contribution of the anterior cingulate cortex to laser-pain conditioning in rats. Brain Res 970: 58-72, 2003.

Kuo CC, Yen CT. Comparison of anterior cingulate and primary somatosensory neuronal responses to noxious laser-heat stimuli in conscious, behaving rats. J Neurophysiol 94: 1825-1836, 2005.

LaGraize SC, Labuda CJ, Rutledge MA, Jackson RL, Fuchs PN. Differential effect of anterior cingulate cortex lesion on mechanical hypersensitivity and escape/avoidance behavior in an animal model of neuropathic pain. Exp Neurol 188: 139-148, 2004

Lamour Y, Guilbaud G, Willer JC. Rat somatosensory (SmI) cortex: II. Laminar and columnar organization of noxious and non-noxious inputs. Exp Brain Res 49: 46-54, 1983a.

Lamour Y, Willer JC, Guilbaud G. Neuronal responses to noxious stimulation in rat somatosensory cortex. Neurosci Lett 29: 35-40, 1982.

Lamour Y, Willer JC, Guilbaud G. Rat somatosensory (SmI) cortex: I. Characteristics of neuronal responses to noxious stimulation and comparison with responses to non-noxious stimulation. Exp Brain Res 49: 35-45, 1983 b.
Liang KC. Pre- or post-training injection of buspirone impaired retention in the inhibitory avoidance task: involvement of amygdala 5-HT1A receptors. Eur J Neurosci 11: 1491-1500, 1999.

Malin EL, Ibrahim DY, Tu JW, McGaugh JL. Involvement of the rostral anterior cingulate cortex in consolidation of inhibitory avoidance memory: interaction with the basolateral amygdala. Neurobiol Learn Mem 87: 295302, 2007.

Malin EL, McGaugh JL. Differential involvement of the hippocampus, anterior cingulate cortex, and basolateral amygdala in memory for context and footshock. Proc Natl Acad Sci USA 103: 1959-1963, 2006.

Marschner A, Kalisch R, Vervliet B, Vansteenwegen D, Buchel C. Dissociable roles for the hippocampus and the amygdala in human cued versus context fear conditioning. J Neurosci 28: 9030-9036, 2008.

Melzack R, Casey KL. Sensory, motivational and central control determinants of pain. In: The Skin Senses, edited by Kenshalo DR. Springfield, IL: Charles C Thomas, 1968, p. 423-443.

Merzenich MM, Nelson RJ, Stryker MP, Cynader MS, Schoppmann A, Zook JM. Somatosensory cortical map changes following digit amputation in adult monkeys. J Comp Neurol 224: 591-605, 1984.

Miserendino MJ, Sananes CB, Melia KR, Davis M. Blocking of acquisition but not expression of conditioned fear-potentiated startle by NMDA antagonists in the amygdala. Nature 345: 716-718, 1990.

Paxinos G, Watson C. The Rat Brain in Stereotaxic Coordinates (4th ed.). San Diego, CA: Academic Press, 1998.

Phan KL, Wager T, Taylor SF, Liberzon I. Functional neuroanatomy of emotion: a meta-analysis of emotion activation studies in PET and fMRI. Neuroimage 16: 331-348, 2002.

Pillay PK, Hassenbusch SJ. Bilateral MRI-guided stereotactic cingulotomy for intractable pain. Stereotact Funct Neurosurg 59: 33-38, 1992.

Porro CA, Cettolo V, Francescato MP, Baraldi P. Temporal and intensity coding of pain in human cortex. J Neurophysiol 80: 3312-3320, 1998.

Price DD, Dubner R. Neurons that subserve the sensory-discriminative aspects of pain. Pain 3: 307-338, 1977.

Rainville P, Duncan GH, Price DD, Carrier B, Bushnell MC. Pain affect encoded in human anterior cingulate but not somatosensory cortex. Science 277: 968-971, 1997.

Recanzone GH, Merzenich MM, Schreiner CE. Changes in the distributed temporal response properties of SI cortical neurons reflect improvements in performance on a temporally based tactile discrimination task. J Neurophysiol 67: 1071-1091, 1992

Recanzone GH, Schreiner CE, Merzenich MM. Plasticity in the frequency representation of primary auditory cortex following discrimination training in adult owl monkeys. J Neurosci 13: 87-103, 1993.

Sananes CB, Davis M. N-Methyl-D-aspartate lesions of the lateral and basolateral nuclei of the amygdala block fear-potentiated startle and shock sensitization of startle. Behav Neurosci 106: 72-80, 1992.

San Pedro EC, Mountz JM, Mountz JD, Liu HG, Katholi CR, Deutsch G. Familial painful restless legs syndrome correlates with pain dependent variation of blood flow to the caudate, thalamus, and anterior cingulate gyrus. J Rheumatol 25: 2270-2275, 1998.

Shaw FZ, Chen RF, Tsao HW, Yen CT. Comparison of touch- and laser heat-evoked cortical field potentials in conscious rats. Brain Res 824: 183-196, 1999.

Shaw FZ, Chen RF, Yen CT. Dynamic changes of touch- and laser heatevoked field potentials of primary somatosensory cortex in awake and pentobarbital-anesthetized rats. Brain Res 911: 105-115, 2001.

Shi C, Davis M. Pain pathways involved in fear conditioning measured with fear-potentiated startle: lesion studies. J Neurosci 19: 420-430, 1999.

Sikes RW, Vogt BA. Nociceptive neurons in area 24 of rabbit cingulate cortex. J Neurophysiol 68: 1720-1732, 1992.

Tang J, Ko S, Ding H-K, Qiu C-S, Calejesan A, Zhuo M. Pavlovian fear memory induced by activation in the anterior cingulate cortex. Mol Pain 1: Record 6, 2005.

Tischler MD, Davis M. A visual pathway that mediates fear-conditioned enhancement of acoustic startle. Brain Res 276: 55-71, 1983.

Tsai ML, Kuo CC, Sun WZ, Yen CT. Differential morphine effects on shortand long-latency laser-evoked cortical responses in the rat. Pain 110: 665-674, 2004

Tsai ML, Yen CT. A simple method for fabricating horizontal and vertical microwire arrays. J Neurosci Methods 131: 107-110, 2003.

Vaccarino AL, Melzack R. Analgesia produced by injection of lidocaine into the anterior cingulum bundle of the rat. Pain 39: 213-219, 1989. 
Vogt BA, Derbyshire S, Jones AK. Pain processing in four regions of human cingulate cortex localized with co-registered PET and MR imaging. Eur J Neurosci 8: 1461-1473, 1996.

Wang JY, Luo F, Chang JY, Woodward DJ, Han JS. Parallel pain processing in freely moving rats revealed by distributed neuron recording. Brain Res 992: 263-271, 2003.

Weinberger NM. Specific long-term memory traces in primary auditory cortex. Nat Rev Neurosci 5: 279-290, 2004.

Wong ET, Gunes S, Gaughan E, Patt RB, Ginsberg LE, Hassenbusch SJ, Payne R. Palliation of intractable cancer pain by MRI-guided cingulotomy. Clin J Pain 13: 260-263, 1997.
Yamamura H, Iwata K, Tsuboi Y, Toda K, Kitajima K, Shimizu N, Nomura H, Hibiya J, Fujita S, Sumino R. Morphological and electrophysiological properties of ACCx nociceptive neurons in rats. Brain Res 735: 83-92, 1996.

Yen CT, Huang CH, Fu SE. Surface temperature change, cortical evoked potential and pain behavior elicited by $\mathrm{CO}_{2}$ lasers. Chin J Physiol 37: 193-199, 1994.

Youell PD, Wise RG, Bentley DE, Dickinson MR, King TA, Tracey I, Jones AK. Lateralisation of nociceptive processing in the human brain: a functional magnetic resonance imaging study. Neuroimage 23: 1068-1077, 2004. 